Gazi University
Journal of Science
http://dergipark.gov.tr/gujs

\title{
Robust Reference Tracking and Load Rejection on Non-Linear System Using Controllers
}

\author{
Renjini G.S , * (D), Deepa THANGAVELUSAMY $^{2}$ (D) \\ ${ }^{l}$ Industrial Electric \& Control Systems, SVG Electric \& Control Products, Perumal Kovil Street, Barur (PO), Krishnagiri (Dt), Tamil Nadu, \\ India \\ ${ }^{2}$ SELECT, VIT University, Chennai, India.
}

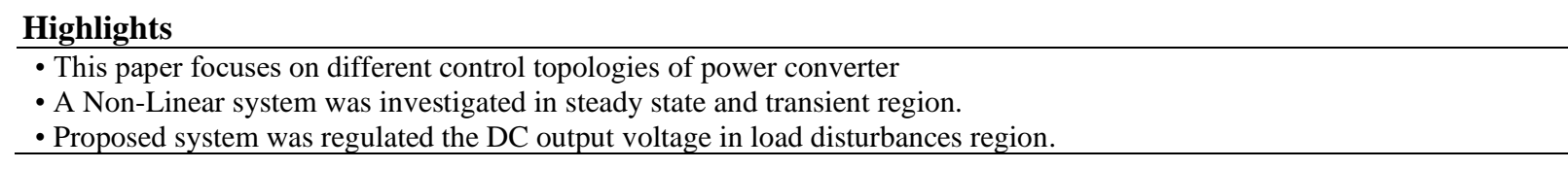

\begin{tabular}{|c|}
\hline Article Info \\
\hline $\begin{array}{l}\text { Received: } 04 \text { June } 2021 \\
\text { Accepted: } 17 \text { Oct } 2021\end{array}$ \\
\hline Keywords \\
\hline $\begin{array}{l}\text { Positive output elementa } \\
\text { luo converter, } \\
\text { Proportional integral } \\
\text { controller, } \\
\text { Linear quadratic } \\
\text { regulator, } \\
\text { Integral absolute error, } \\
\text { Integral square error }\end{array}$ \\
\hline
\end{tabular}

\section{INTRODUCTION}

DC-DC converters are widely used in battery power applications in many areas. For multiple battery mission requires large storage space and also its stored energy starts to decay when the voltage is drained. This drawback is overcome by using switched DC-DC converters. The second-generation converters utilize the positive, negative and dual-output of single quadrant Luo converter to acquire the bidirectional power flow with higher efficiency. In addition with a novel geometric progression was introduced for the lifting of voltage to achieve high voltage gain using a simple structure in a cascade converter. Besides with conventional converter filter components are connected to reduce radio frequency interference. The advantage of this proposed converter has been verified by comparing it with existing converters via simulation and hardware setup $[1,2]$.

The Numerous control approaches and tuning methods are used to regulate the load voltage constant for servo as well as regulatory responses. The conventional PI control techniques are commonly used in much Industrial application. Combination of proportional and integral gain constitutes PI controller. Zeigler Nichols $(\mathrm{ZN})$ is one of the most prevalent methods used to determine the proportional gain and the Integral gain [3-6]. This controller provides stable operation against load disturbances and minimizes the saturation risk. The unstable equilibrium point is removed from the balance dynamics. PI controller for POESLL

\begin{abstract}
-DC converters form a class of highly nonlinear systems and are widely used in most practica used to regulate dc voltages in low power applications with varying input voltage and load powering hard diss etc. The to the highly nonlinear nature of these converters. Hence the development of an optimal controlle and steady-state performances considering practical operating conditions. The controllers are designed, simulated and the performance of POELC with various controllers is evaluated in the to regulate the output of POELC. The result shows that a well-designed LQR feedback can stabilize the system and enhances its performance in terms of Integral Absolute Error (IAE), Integral Square Error (ISE). Certain case studies are discussed concerning practical applications.
\end{abstract}


converter to attain static and dynamic performance over Proportional Integral and Derivative (PID) controller. The mathematical modelling of the converter and controller are performed by the state-space averaging method [7]. PI Controller provides poor performance for Non-linear system. So this kind of system requires some expertise knowledge like fuzzy logic for better performance system. From the literature survey [8-10], comparative study of FLC based PI controller with another controller in terms of transient response, steady-state error, disturbance rejection from the load and current variations are studied in different closed-loop systems. These feedback systems provide regulated boosted output voltage. The simulation reveals that superior performance is exhibited by the proposed controller. But these controllers do not forecast the future behaviour of the Non-linear system. Hence predictive voltage controller is used to suppressing cross-regulation issues in a single-input multiple-output buck converter. The converter operates in Continuous Conduction Mode (CCM) and has quick dynamic responses, adaptable to variable switching frequency [11]. This controller can improve the steady-state error at low frequency. Even though with simple construction, less computation and fixed frequency, this controller is not robust against load variation and signal disturbances and also this system provides poor performance indices for load disturbance regions [12].

Most of the early works done in this area focused more on finding PID controllers that stabilize the nominal plant model. Many authors continued their research by using intelligent control techniques like Fuzzy, SMC etc. Some of the authors extended their research work to optimize the PID controller parameter which will meet certain design criteria and provide robustness. The beginning of PID controller is more than fivedecade-old and at present, its functionality has been furthermore improvised with an aid of advanced control techniques like Model Predictive Controller, Robust controller etc. which deal with issues like stability, efficient computation, optimization, constraints etc. But the control of the higher-order plant is always a challenging task due to its highly nonlinear nature. System designed using optimal LQR balances between acceptable response and the amount of control energy required [13].

Find a feasible control, such that the system that starts from the given initial condition transfer its state to the objective set, and in so doing minimizes a performance index. In industrial systems, there are some situations such as the improving optimal use of available resources, chemical process, traffic control systems and robotic systems where optimal control can be applied, such as the control of bacterial content in a bioengineering system [14].

Linear Quadratic Regulator shows better performance indices for the system which undergoes various uncertain parameters like source voltage, load and duty ratio. The weight matrices of the cost function are determined using various methods. It determines the error and energy expense rate of the system. Compared with the existing methods, this method shows superior performance like less settling time, minimum amplitude control signal with less error. The results are not verified experimentally to validate the simulation performance $[15,16]$. The dynamic parameters such as source and reference voltages along with load current are varied to measure the response of the controllers. The peak overshoot, undershoot and reverse recovery time are measured to find the competence of the LQR. The simulation models were developed to analyze the transient and steady-state performances. Literature surveys enlighten the necessity of the controllers for the Non-linear system [17].

In this paper, Positive Output Elementary Luo Converter (POELC) is considered as a Single Input Single Output (SISO) system. POELC provides good steady-state performance characteristics. But its dynamic performance is affected due to the fourth-order characteristics which lead to closed-loop bandwidth limitation for large-signal stabilization. Hence conventional PIC and LQR techniques are incorporated to converter for better performance. Section 2 details the power converter operation, descriptions and design parameters. Section 3 and 4 illustrate the control topologies such as PIC and LQR. Section 5 describes the simulation results and Section 6 details the conclusion of this paper.

\section{POWER CONVERTER}

Power Electronics is an emerging technology that provides an interface between the source and the load to transfer power. Most of the utility mains require very low voltages internally. This low voltage is achieved 
by the use of Switched Mode Power Supplies (SMPS). The major role of DC-DC converters is to transfer power from the source to load. The Switched-mode DC-DC converters are used for converting voltage from one level to another by switching action. They are widely used in SMPS and DC motor drive applications. The output voltage of the converter should be regulated against source voltages and load perturbations. By switching the on and off duration of the switching pulse, the converter generates an average output dc voltage. But there are some drawbacks to the fundamental DC-DC converter used in SMPS. The efficiency of the converters is very poor for high gain and also it is very difficult to control and analyze. The control of higher-order converters is always a challenging task due to the highly nonlinear nature of these converters. Moreover, the effect of noise and Electro-Magnetic Interference (EMI) is quite significant, thus EMI filters are also required. Positive Output Elementary Luo Converter (POELC) overcomes these drawbacks and also it is efficiently used in SMPS for 200W [18].

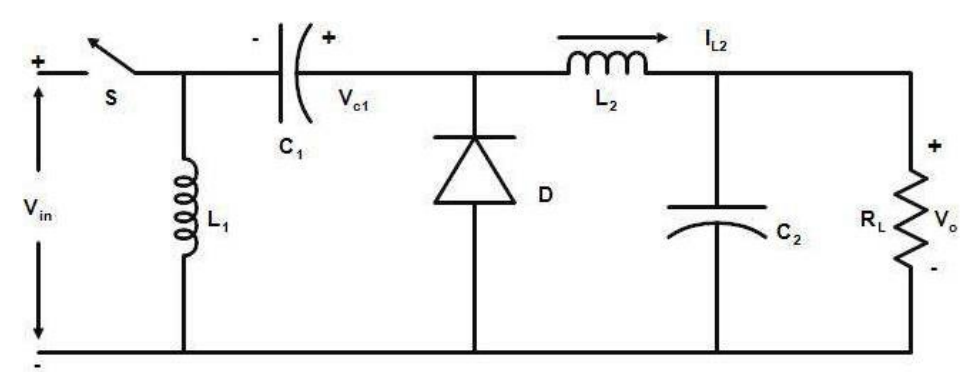

Figure 1. Positive output elementary Luo converter

Figure 1 shows the circuit diagram of POELC. This is a direct positive output buck-boost converter. The components consist of inductors $\mathrm{L}_{1}, \mathrm{~L}_{2}$, capacitors $\mathrm{C}_{1}, \mathrm{C}_{2}$, freewheeling diode $\mathrm{D}$, and the power switch $\mathrm{S}$. The load resistance $R_{L}$ is working on the switching frequency $F_{s}$ with duty ratio $\delta$ for source voltage $V_{\text {in }}$ and the output voltage $\mathrm{V}_{\mathrm{o}}$. It consists of, $\mathrm{S}-\mathrm{L}_{1}-\mathrm{C}_{1}-\mathrm{D}$ act as pump circuit and $\mathrm{L}_{2}-\mathrm{C}_{2}$ act as low pass filter. Capacitor $\mathrm{C}_{1}$ has a sufficiently large value to store and transfer energy. The converter operates in two modes [19].

\subsection{Switch on Condition}

Figure 2 illustrates POELC in on mode. When the switch is closed, the current flowing through the inductor $\mathrm{L}_{1}$ starts increasing for the supply voltage. Energy stored in capacitor $\mathrm{C}_{1}$ is transferred to the load through the inductor $\mathrm{L}_{2}$. The load is supplied by capacitor $\mathrm{C}_{2}$. Since the diode $\mathrm{D}$ is reverse biased, the inductor currents $i_{L 1}$ and $i_{L 2}$ increase until the switch $S$ is turned off. The Equations (2) to (5) are derived by using Kirchoff Voltage Law (KVL) and Kirchoff Current Law (KCL) for POELC during the switch-on condition.

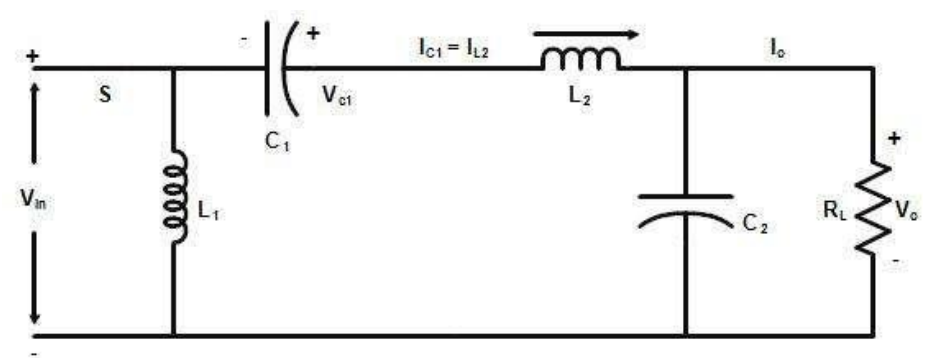

Figure 2. POELC-Switch on mode

$\partial=\left\{\begin{array}{c}1 ; 0 \leq t \leq k T \\ 0 ; k t \leq t \leq T\end{array}\right\}$

$\frac{d i_{L 1}}{d t}=\frac{E}{L_{1}}$

$\frac{d i_{L 2}}{d t}=\frac{E-V_{c 1}-V_{c 2}}{L_{2}}$ 


$$
\begin{aligned}
& \frac{d V_{c 1}}{d t}=-\frac{i_{L 2}}{C_{1}} \\
& \frac{d V_{C 2}}{d t}=\frac{i_{L 2}}{C_{2}}-\frac{V_{c 2}}{R C_{2}}
\end{aligned}
$$

\section{where}

$\mathrm{i}_{\mathrm{L} 1}$ - The inductor current $\mathrm{L}_{1}$,

$\mathrm{i}_{\mathrm{L} 2}$ - The inductor current $\mathrm{L}_{2}$,

$\mathrm{V}_{\mathrm{c} 1}$ - The capacitor voltage $\mathrm{C}_{1}$,

$\mathrm{V}_{\mathrm{c} 2}$ - The capacitor voltage $\mathrm{C}_{2}$,

$\mathrm{V}_{\text {in }}$ - Input voltage.

\subsection{Switch off Condition}

Figure 3 implies that the energy stored in the inductors $L_{1}$ and $L_{2}$ is transferred to the capacitor $C_{1}$ and $C_{2}$, $\mathrm{R}$ through the respectively. Freewheeling diode $\mathrm{D}$ is used for continuous conduction mode. Equations (6) to (9) explains the circuit dynamics under mode 2 are obtained by applying the KCL and KVL.

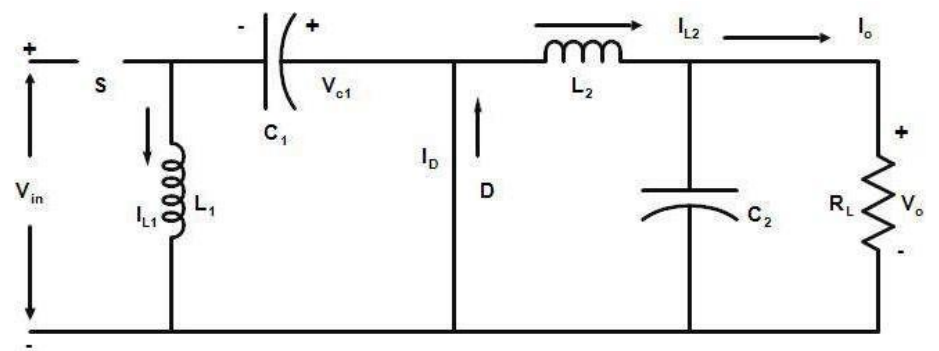

Figure 3. POELC-Switch off mode

$$
\begin{aligned}
& \frac{d i_{L 1}}{d t}=-\frac{V_{c 1}}{L_{1}} \\
& \frac{d i_{L 2}}{d t}=\frac{-V_{c 2}}{L_{2}} \\
& \frac{d V_{C 1}}{d t}=\frac{i_{L 1}}{C_{1}} \\
& \frac{d V_{c 2}}{d t}=\frac{i_{L 2}}{C_{2}}-\frac{V_{c 2}}{R C_{2}} .
\end{aligned}
$$

The final state space equivalent matrices A, B, C, D of the converter derived from the Equations (2) to (9) are given below 


$$
\left[\begin{array}{c}
\frac{d V_{c 2}(t)}{d t} \\
\frac{d i_{L 2(t)}}{d t} \\
\frac{d V_{c 1(t)}}{d t} \\
\frac{d i_{L 1(t)}}{d t}
\end{array}\right]=\left[\begin{array}{cccc}
-\frac{1}{R C_{2}} & \frac{1}{C_{2}} & 0 & 0 \\
-\frac{1}{L_{2}} & 0 & \frac{\partial}{L_{2}} & 0 \\
0 & -\frac{\partial}{C_{1}} & 0 & \frac{(1-\partial)}{C_{1}} \\
0 & 0 & \frac{(1-\partial)}{L_{1}} & 0
\end{array}\right]\left[\begin{array}{c}
V_{c 2} \\
i_{L 2} \\
V_{c 1} \\
i_{L 1}
\end{array}\right]+\left[\begin{array}{c}
0 \\
\frac{\partial}{L_{2}} \\
0 \\
\frac{\partial}{L_{1}}
\end{array}\right] V_{i n} .
$$

\subsection{Design of Converter Components}

The mathematical model of the converter is derived by the state space average method in which the state equation is derived for the power switch conduction period and the diode conduction period. Assuming the design parameters of the POELC for output voltage $\mathrm{V}_{\mathrm{o}}=24 \mathrm{~V}$ for the proposal values of input voltage $\mathrm{V}_{\text {in }}$ $=12 \mathrm{~V}$, Frequency $\mathrm{F}_{\mathrm{s}}=50 \mathrm{KHz}$, Inductor $\mathrm{L}_{1}=\mathrm{L}_{2}=1 \mathrm{mH}$, Capacitors $\mathrm{C}_{1}=\mathrm{C}_{2}=10 \mu \mathrm{F}$, Duty cycle $\partial=0.5$, Resistance $\mathrm{R}_{\mathrm{L}}=2.8 \Omega$, Output Power $\mathrm{P}_{\mathrm{o}}=200 \mathrm{~W}$.

DC voltage conversion ratio $\mathrm{M}$

$$
\mathrm{M}=\frac{\mathrm{V}_{\mathrm{o}}}{\mathrm{V}_{\mathrm{in}}}=1
$$

The ripple current in inductor $\mathrm{L}_{1}$

$$
\varepsilon_{1}=\frac{(1-\partial) \mathrm{R}_{\mathrm{L}}}{2 \mathrm{MF}_{\mathrm{s}} \mathrm{L}_{1}}=0.1
$$

The ripple current in inductor $\mathrm{L}_{2}$

$$
\varepsilon_{2}=\frac{\partial \mathrm{R}_{\mathrm{L}}}{2 \mathrm{MF}_{\mathrm{S}} \mathrm{L}_{2}}=0.4
$$

The ripple voltage in Capacitor $\mathrm{C}_{1}$

$$
\rho_{1}=\frac{\partial}{2 \mathrm{~F}_{\mathrm{s}} \mathrm{R}_{\mathrm{L}} \mathrm{C}_{1}}=0.0025 .
$$

The ripple voltage in Capacitor $\mathrm{C}_{2}$

$$
\rho_{2}=\frac{\delta}{8 \mathrm{MF}_{\mathrm{s}}{ }^{2} \mathrm{C}_{2} \mathrm{~L}_{2}}=0.00125 .
$$

Table 1. Design Parameters of POELC-SMPS

\begin{tabular}{|l|l|l|l|l|l|l|l|}
\hline Components & $\begin{array}{l}\text { Inductor } \\
\mathrm{L}_{1}\end{array}$ & $\begin{array}{l}\text { Inductor } \\
\mathrm{L}_{2}\end{array}$ & $\begin{array}{l}\text { Capacitor } \\
\mathrm{C}_{1}\end{array}$ & $\begin{array}{l}\text { Capacitor } \\
\mathrm{C}_{2}\end{array}$ & $\begin{array}{l}\text { Resistor } \\
\mathrm{R}_{\mathrm{L}}\end{array}$ & $\begin{array}{l}\text { Switching } \\
\text { Frequency } \\
\mathrm{F}_{\mathrm{s}}\end{array}$ & $\begin{array}{l}\text { Input } \\
\text { Voltage } \\
\mathrm{V}_{\text {in }}\end{array}$ \\
\hline $\begin{array}{l}\text { Ratings of } \\
\text { Components }\end{array}$ & $1 \mathrm{mH}$ & $1 \mathrm{mH}$ & $10 \mu \mathrm{F}$ & $10 \mu \mathrm{F}$ & $2.8 \Omega$ & $50 \mathrm{KHz}$ & $12 \mathrm{~V}$ \\
\hline
\end{tabular}

In POELC the power stage contains the inductors and capacitors which introduce nonlinearity and their behaviour cannot be judged easily. Therefore there is a necessity to linearize a nonlinear system. Linearization is a method for assessing the local stability of an equilibrium point of a system of nonlinear differential equations or discrete dynamical systems [20]. To linearize the system, small perturbations in 
the variables are considered. From 0.4 to 0.5 duty cycle, around the operating point, the converter exhibits linear characteristics. Hence a duty cycle of 0.5 is chosen. The design values for POELC components are tabulated in Table 1. These values are substituted in the system state space matrix Equations (2) to (9) and the output to control input transfer function is obtained as,

$$
\frac{V_{O}(s)}{V_{\text {in }}(s)}=\frac{4.86 * 10^{10} s^{2}-0.00017 s+7.29 * 10^{20}}{s^{4}+5.79 * 10^{5} s^{3}+8.4 * 10^{10} s^{2}+8.5 * 10^{15} s+3.13 * 10^{20}} .
$$

Zeros are

$\mathrm{s}_{1}=0.0000+122470 \mathrm{i}, \mathrm{s}_{2}=0.0000-122470 \mathrm{i}$.

\section{Poles are}

$\mathrm{s}_{1}=-423280, \mathrm{~s}_{2}=-48670+101700 \mathrm{i}, \mathrm{s}_{3}=-48670-101700 \mathrm{i}, \mathrm{s}_{4}=-58080$.

It is observed that the open-loop system has four negative poles out of which two are negative real poles and the other two are complex poles. Hence the system is stable. Even though it is a stable system, it exhibits nonlinear behaviour when subjected to disturbances. These parameters change with time causing the converter operating point to change. Hence the converter operation may deviate from the steady-state condition. Controllers are incorporating into the power converter for obtaining stabled controlled operation for a wide operating range and are also used to achieve satisfactory static and dynamic performance [21]. Non-zero error is important for any closed-loop system. Hence to find Integral Absolute Error (IAE) to be more appropriate. In the case of Integral Square Error (ISE), the square-of-error converges to zero. The main objective function is to optimize the controller parameters that minimize the IAE and ISE criteria.

Mathematically it is represented by,

$$
\begin{aligned}
& I A E=\int_{0}^{\infty} a b s(r(t)-y(t)) d t \\
& I S E=\int_{0}^{\infty}(r(t)-y(t))^{2} d t
\end{aligned}
$$

where $r(t)$ - reference input signal, $y(t)$ - measured output signal.

\section{PI CONTROLLER}

Proportional Integral Controller (PIC) is a feedback controller which obtains the error and determines the output based on the characteristics of the error signal. The difference between the reference variable $r(t)$ and the process variable $\mathrm{y}(\mathrm{t})$ is given as error signal $\mathrm{e}(\mathrm{t})$ which are evaluated and measured to get the output. This output signal $u(t)$ is given as the controlled input for the converter. Proportional Controller (PC) introduces the steady-state error. The increase in gain reduces the error. But it makes the system oscillatory. The consequence of summing integral controller introduces a pole and reduces the steady-state error [22]. The block diagram of the PIC designed for POELC is represented in Figure 4.

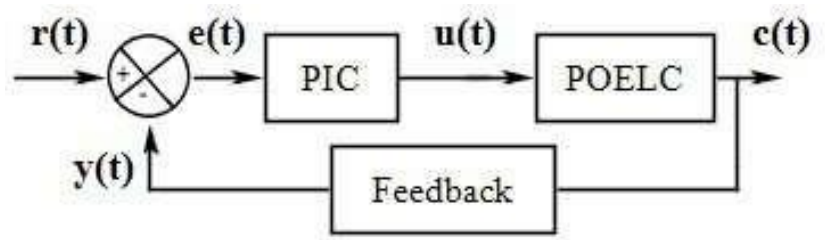

Figure 4. Block diagram of PIC for POELC 
The structure of the PI control system is

$$
\begin{aligned}
& u(t)=K_{p} e(t)+K_{i} \int_{0}^{t} e(t) d t \\
& u(t)=K_{p} e(t)+\frac{K_{p}}{T_{i}} \int_{0}^{t} e(t) d t
\end{aligned}
$$

where $e(t)=r(t)-y(t) ; u(t)$ - controlled input signal,e $(t)$ - error signal.

For the past five decades, several tuning methods were developed for calculating the PIC parameters. One of the renowned tuning procedures is ZN method. In this method, the proportional gain is varied by keeping the Integral value as zero-till sustained oscillations are obtained. The step response of the open-loop transfer function is presented in Figure 5. Appling $\mathrm{ZN}$ method, time delay $\mathrm{L}=0.000004 \mathrm{~s}$ and the time constant $\mathrm{a}=0.28$ is observed. Substituting these values into equation $\mathrm{Kp}=0.9 / \mathrm{a}=3.214$, $\mathrm{Ti}=3 \mathrm{~L}=0.012 \mathrm{~ms}$ are calculated

$$
\begin{aligned}
& K(s)=K_{p}\left(1+\frac{1}{T_{i} s}\right) \\
& K(s)=3.214+\frac{267857}{s} .
\end{aligned}
$$

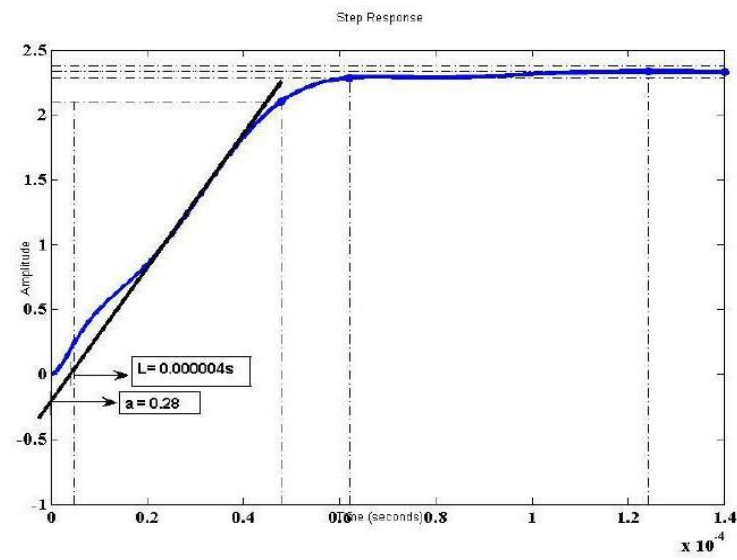

Figure 5. Step response of the open loop transfer function

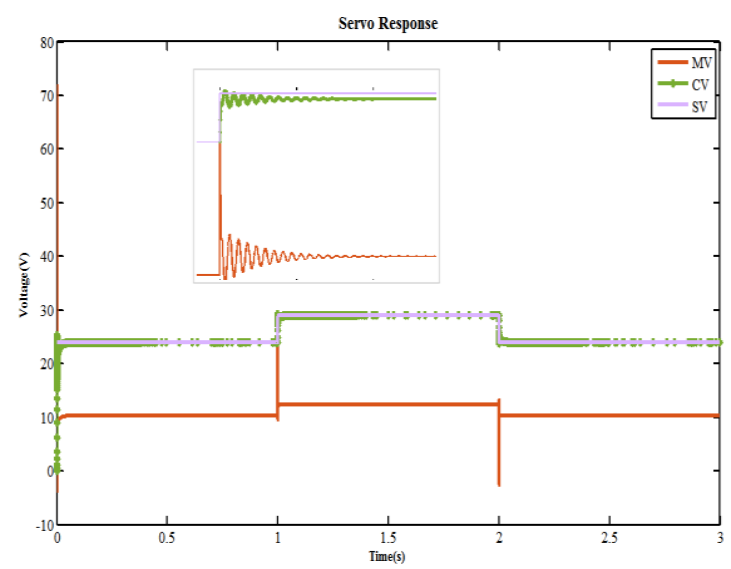

Figure 6. Servo Response of PIC for POELC-SMPS 
The optimal setting values of PIC are attained by the ZN method for desired performance. Figure 6 shows the servo response of PIC for POELC. The reference voltages or Set Points (SP) are set as $24 \mathrm{~V}$ at $0 \mathrm{~s}, 29 \mathrm{~V}$ at $1 \mathrm{~s}$ and $24 \mathrm{~V}$ at $2 \mathrm{~s}$ of interval. The Control Variable (CV) and the Manipulated Variable (MV) for the corresponding reference voltages are mentioned graphically.

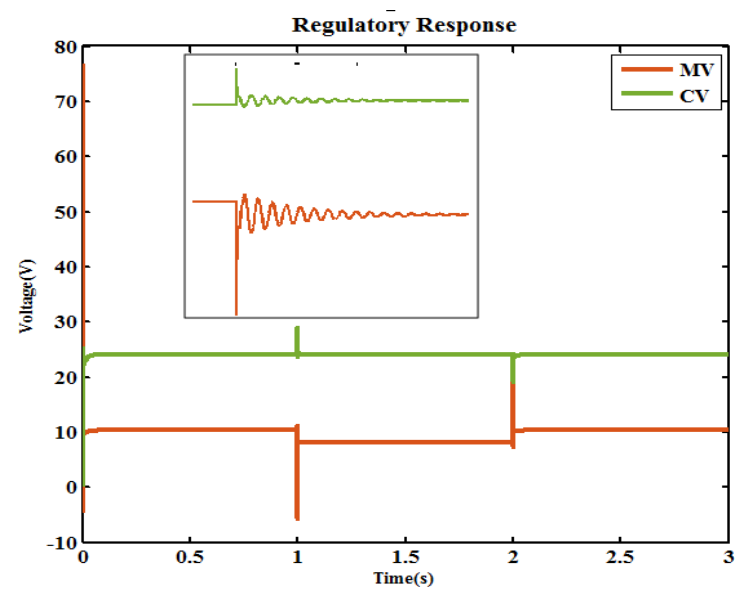

Figure 7. Regulatory Response of PIC for POELC-SMPS

Figure 7 depicts the regulatory response of PIC for POELC. The load is increased and decreased by $20 \%$ of the interval of $1 \mathrm{~s}$. Responses show oscillation of higher amplitudes and later on, it subsides with time. The settling time of the response is more.

\section{LINEAR QUADRATIC REGULATOR}

Linear Quadratic Regulator (LQR) is the linear controller mainly designed for better quadratic performances. The system designed by using optimal controller where the closed-loop poles are allocated such that dominant poles move towards the Left Half of the s-Plane (LHP) then the remaining poles are non-dominant. Hence it makes the system less sensitive in the disturbance regions.

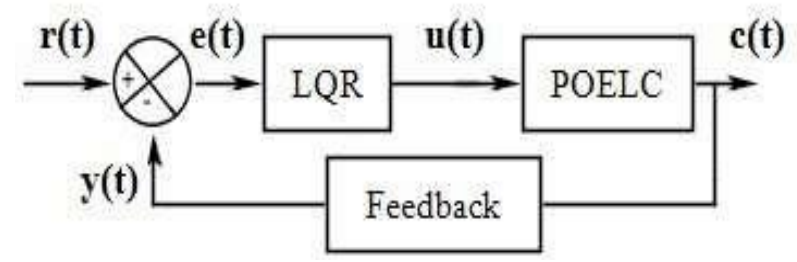

Figure 8. Block diagram of $L Q R$ for POELC

State-space modelling is used for the easy representation of the system. This controller has performed well in both steady- state and transient conditions [23]. Feedback control law is defined by,

$$
\mathrm{u}=-\mathrm{Kx}(\mathrm{t})
$$

In this technique, the feedback gain matrix $(\mathrm{K})$ is determined by optimizing $\mathrm{J}$ energy function

$$
J=\int_{0}^{\infty}\left(x^{T} Q x+u^{T} R u\right) d t
$$

Matrices $\mathrm{Q}$ and $\mathrm{R}$ express the relationship between error and energy expense rate. Optimal control gain $\mathrm{K}$ is given by, 


$$
\mathrm{K}=\mathrm{R}^{-1} \mathrm{~B}^{\mathrm{T}} \mathrm{P} .
$$

Thus the optimal control law is given by,

$$
u=-R^{-1} B^{T} P x(t) .
$$

In addition to the state feedback gain $\mathrm{K}, \mathrm{LQR}$ returns the solution $\mathrm{P}$ of the associated reduced matrix Riccati equation is given as follows,

$$
A^{T} P+P A-P B R^{-1} B^{T} P+Q=0 .
$$

Figure 8 shows the block diagram of LQR in POELC. From the Equations (2) to (9), the system matrices $\mathrm{A}, \mathrm{B}, \mathrm{C}, \mathrm{D}$ of the POELC for the corresponding design values mentioned in Table 1 are as follows

$$
\begin{aligned}
& \mathrm{A}= \\
& {\left[\begin{array}{cccc}
-578703 & 1666666 & 0 & 0 \\
-41667 & 0 & 29167 & 0 \\
0 & -350000 & 0 & 150000 \\
0 & 0 & -30000 & 0
\end{array}\right]} \\
& \mathrm{B}=\left[\begin{array}{c}
0 \\
29167 \\
0 \\
70000
\end{array}\right] \\
& \mathrm{C}=\left[\begin{array}{llll}
1 & 0 & 0 & 0
\end{array}\right] \\
& \mathrm{D}=[0] \text {. }
\end{aligned}
$$

To minimize the performance index $\mathrm{J}$ by using the weighting matrices $\mathrm{Q}$ and $\mathrm{R}$ subject to the constraints,

$$
\begin{aligned}
& x=A x(t)+B u(t) \\
& x\left(t_{0}\right)=x_{0} \\
& y=C x(t) .
\end{aligned}
$$

State variables are represented by,

$$
\begin{aligned}
& x_{1}=v_{c 2} \\
& x_{2}=i_{L 2} \\
& x_{3}=v_{c 1} \\
& x_{4}=i_{L 1} .
\end{aligned}
$$

Output matrix $\mathrm{C}$ denotes that $x_{1}$ is accountable for the servo response of the system such that the optimal gain matrices $\mathrm{K}(1)$ is connected through feed-forward for the system. The regulatory response is controlled by $x_{2}, x_{3}, x_{4}$. The corresponding gain matrixes $\mathrm{K}(2), \mathrm{K}(3)$ and $\mathrm{K}(4)$ are connected as feedback for the system. Solution of Riccati Equation (13), P matrix is given by, 
$\mathrm{P}=1.0 \mathrm{e}^{-5} \times\left[\begin{array}{llll}0.1133 & 0.0011 & 0.0000 & 0.0000 \\ 0.0011 & 0.0023 & 0.0000 & 0.0009 \\ 0.0000 & 0.0000 & 0.0003 & 0.0000 \\ 0.0000 & 0.0009 & 0.0000 & 0.0004\end{array}\right]$

Positive-definite matrix $\mathrm{P}$ will exist only for a stable system. Therefore matrix A-BK is stable. By substituting this matrix $\mathrm{P}$ into Equation (25), optimal gain matrix $\mathrm{K}$ is obtained as detailed below

$$
\mathrm{K}=\left[\begin{array}{llll}
314150 & 5990 & 0 & 0
\end{array}\right] \text {. }
$$

For a stable system, closed loop characteristic equation becomes, $\mathrm{AA}=\mathrm{A}-\mathrm{BB}=0$, where $\mathrm{BB}=\mathrm{B} * \mathrm{~K}$

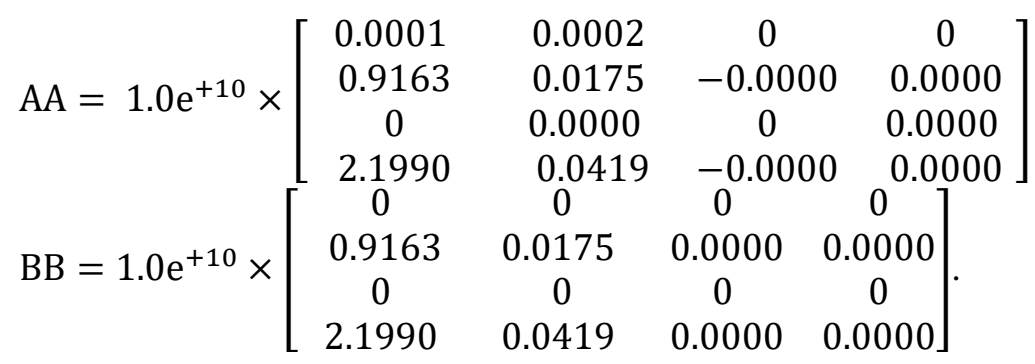

Numeral methods are used to find the weighting matrices Q and R. The weight matrices of the cost function are determined using trial and error method. Q and $\mathrm{R}$ are the positive-definite matrices which are given by,

$$
\begin{aligned}
& Q=\left[\begin{array}{cccc}
100 & 0 & 0 & 0 \\
0 & 0 & 0 & 0 \\
0 & 0 & 0 & 0 \\
0 & 0 & 0 & 0
\end{array}\right] \\
& R=[0.000000001] ; \\
& E=1.0 \mathrm{e}^{+07} \times\left[\begin{array}{l}
-8.7671+8.7671 \mathrm{i} \\
-8.7671-8.7671 \mathrm{i} \\
-0.0000+0.0122 \mathrm{i} \\
-0.0000-0.0122 \mathrm{i}
\end{array}\right] .
\end{aligned}
$$

The LQR engages the choosing of $\mathrm{Q}$ and $\mathrm{R}$ matrix to minimize the energy function which offers adequate performance. The closed-loop eigenvalues were interrelated. This system performance is evaluated in terms of Root locus approach. Figures 9 and 10 illustrate the pole-zero plot of the uncontrolled and controlled plant. The open-loop system has four negative poles out of which two are negative real poles and the other two are complex poles. 


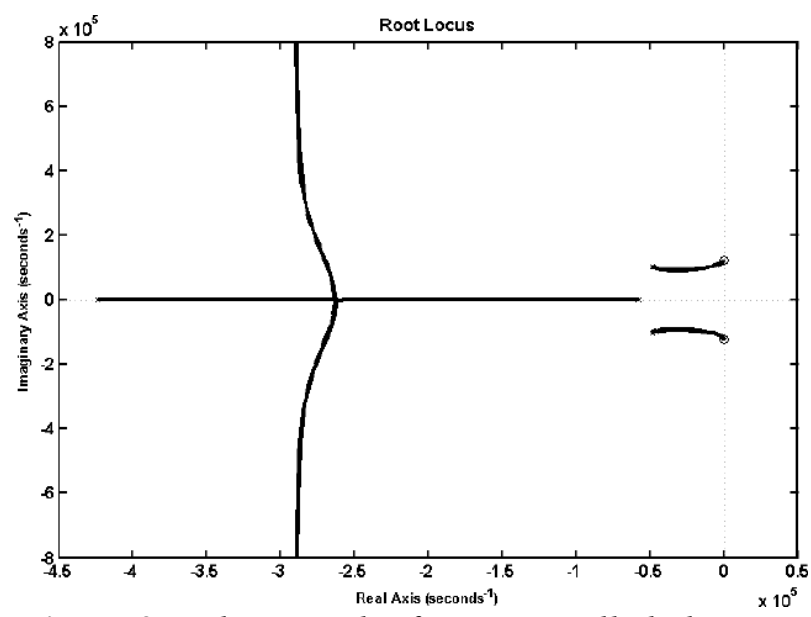

Figure 9. Pole-Zero plot for uncontrolled plant

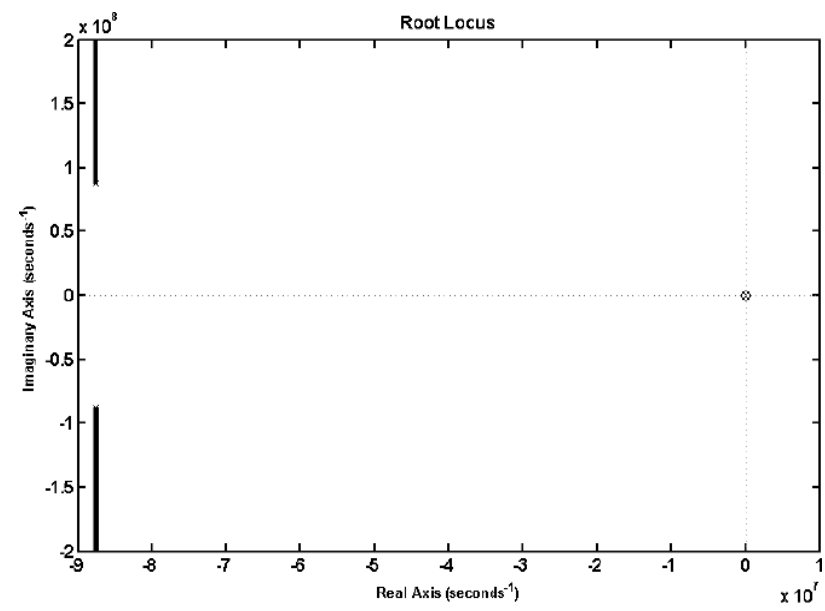

Figure 10. Pole-Zero plot for controlled plant

According to the control theory, if two real poles located near ' $\mathrm{jw}$ ' axis and its magnitude are 5 to 10 times lesser than the real pole located far away from the axis with high amplitude then the former one will be the dominant pole. If the system has a dominant complex pole that affects the transients then it will decay slowly. In pole placement method, poles must be located to the open left half of the complex plane. Hence the location of the closed loop poles on the complex plain is quiet difficult, and requires high level of skills in establishing relationship between poles and dynamic performances of the closed loop control system .If the system equipped with LQR, then it moves the dominant complex poles towards the zeros thereby polezero cancellation takes place. So the system is approximated to the second-order system. Remaining poles will become non-dominant. Hence the system provides improved dynamics in both steady-state and transient regions [24]. Figure 11 shows the servo response of LQR for POELC. The reference voltages or Set Points (SP) are set as $24 \mathrm{~V}$ at $0 \mathrm{~s}, 29 \mathrm{~V}$ at $1 \mathrm{~s}$ and $24 \mathrm{~V}$ at $2 \mathrm{~s}$ of interval. The Control Variable (CV) for the corresponding reference voltages are mentioned graphically. Figure 12 depicts the regulatory response of LQR for POELC. The load is increased and decreased by $20 \%$ of the interval of $1 \mathrm{~s}$.

\section{THE RESEARCH FINDINGS AND DISCUSSION}

Simulations are done for the evaluation of POELC with PIC and LQR using MATLAB. Simulink tool. Proposed POELC is designed for regulating the output voltage of $24 \mathrm{~V}$ for $200 \mathrm{~W}$ SMPS application. The tuning procedure of PIC, LQR is already explained in the previous sections. 


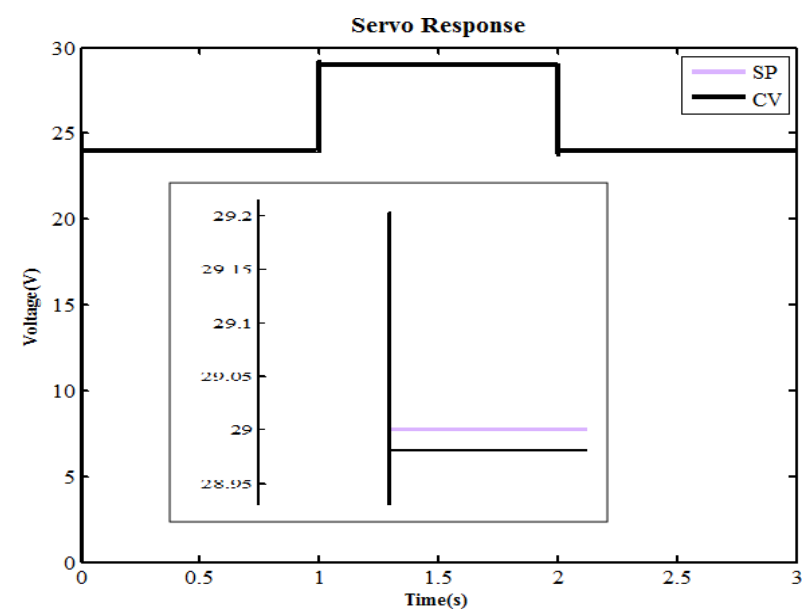

Figure 11. Servo Response of $L Q R$ for POELC

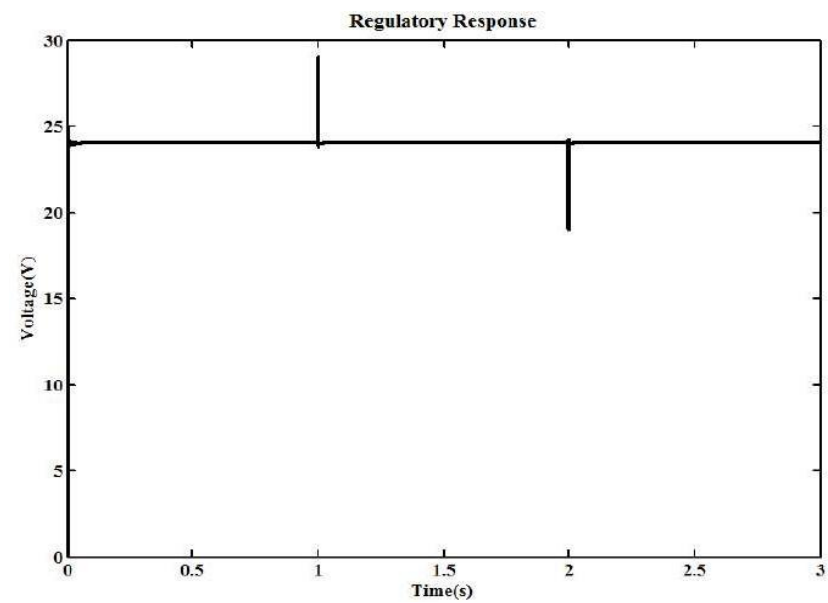

Figure 12. Regulatory Response of $L Q R$ for POELC

In the case of a practical system, feedback control loops in closed-loop systems have time delays. Therefore, the fourth-order system represented in Equation (16) is approximated to First Order system with Deadtime(FOD). The corresponding output to control input transfer function is obtained as,

$$
\begin{aligned}
& \frac{V_{o}(s)}{V_{\text {in }}(s)}=\frac{K e^{-T s}}{(1+T s)} \\
& \frac{V_{o}(s)}{V_{\text {in }}(s)}=\frac{2.4 e^{-0.000004 s}}{(1+0.28 s)}
\end{aligned}
$$

where $\mathrm{K}$ - system gain, $\mathrm{T}$ - dead time, $T$ - time constant. 


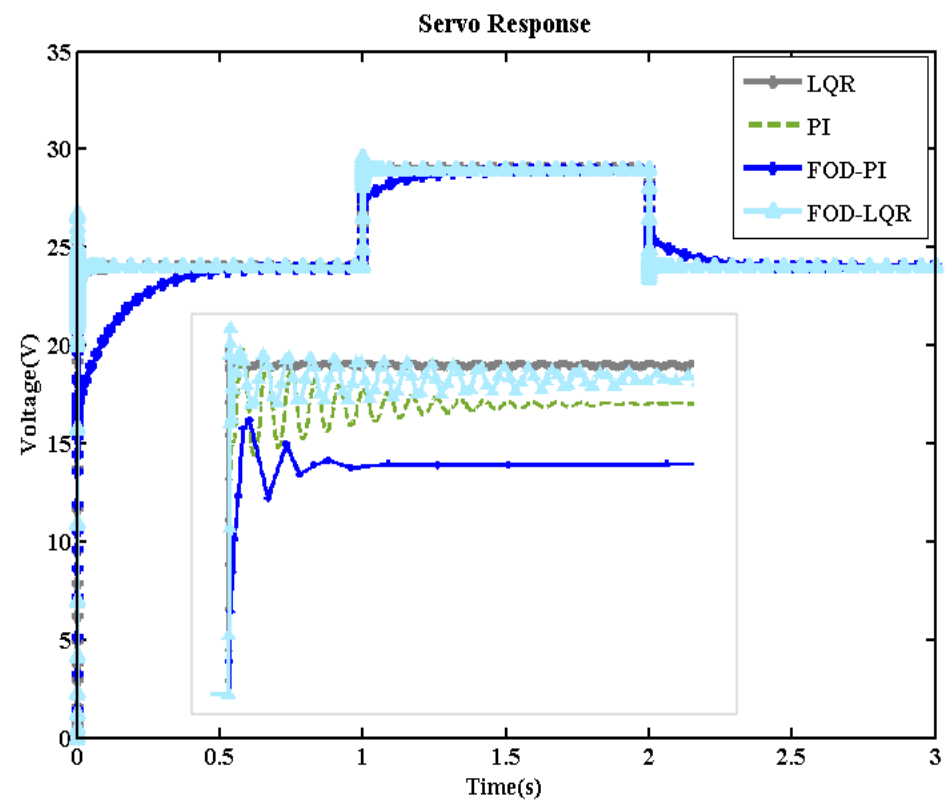

Figure 13. Servo Response of PIC and LQR for POELC

Figure 13 illustrates the servo response of PIC and LQR in POELC. The reference voltage of the system is changed from $24 \mathrm{~V}$ to $29 \mathrm{~V}$ at $1 \mathrm{~s}$ and $29 \mathrm{~V}$ to $24 \mathrm{~V}$ at $2 \mathrm{~s}$. The proposed optimal LQR almost follows the reference values and it shows excellent servo response in both the first-order and fourth-order systems. Figure 14 indicates the regulatory response of PIC and LQR in POELC with load disturbance introduced at $\mathrm{t}=1 \mathrm{~s}$ and $\mathrm{t}=2 \mathrm{~s}$. The disturbance is also shown for characterizing the performance of the system with these two topologies. The proposed LQR controller can achieve the set-point very smoothly even after the load change has occurred for both FOD and higher-order systems.

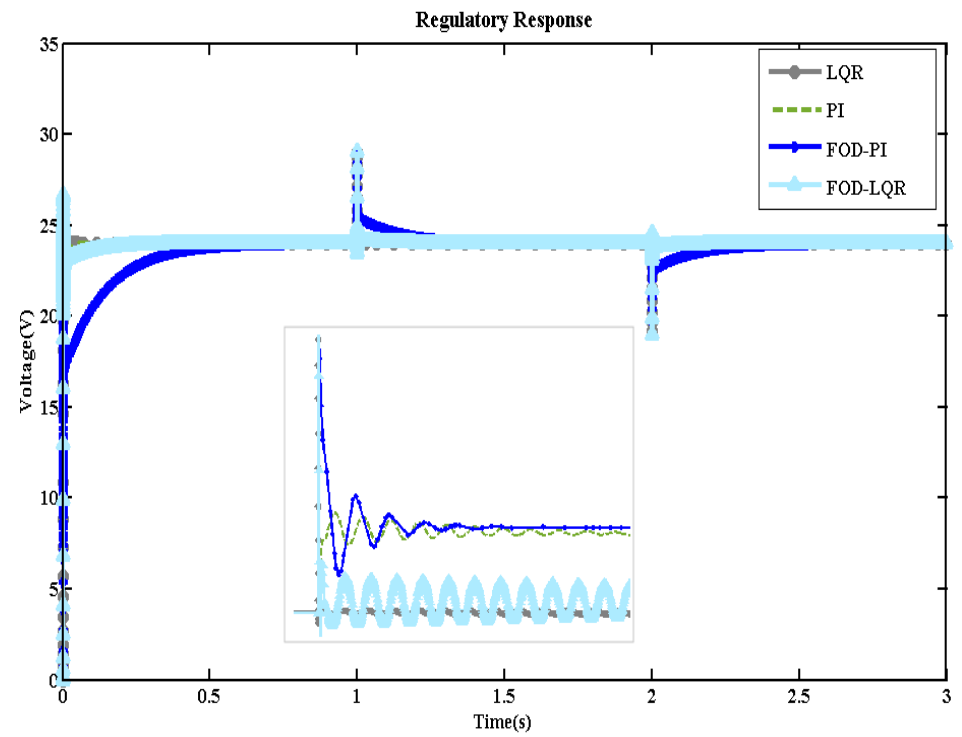

Figure 14. Regulatory Response of PIC and LQR for POELC

Table 2. Time Domain Specification of PIC and LQR for POELC

\begin{tabular}{|l|l|l|l|l|}
\hline $\begin{array}{l}\text { Transient } \\
\text { Response }\end{array}$ & $\begin{array}{l}\text { Rise time } \\
\operatorname{tr}(\mathrm{ms})\end{array}$ & $\begin{array}{l}\text { Peak time } \\
\mathrm{tp}(\mathrm{ms})\end{array}$ & $\begin{array}{l}\text { Peak Overshoot } \\
\mathrm{Mp}(\%)\end{array}$ & $\begin{array}{l}\text { Settling time } \\
\mathrm{ts}(\mathrm{s})\end{array}$ \\
\hline PIC & 1.5 & 1 & 80 & 0.82 \\
\hline LQR & 0.0002 & 0.000006 & 0.5 & 0.000004 \\
\hline
\end{tabular}


Table 2 observes time domain specifications for POELC with PIC and LQR control strategies. Rise time, peak time, maximum peak overshoot and settling times are evaluated for both controller topologies. LQR shows better time response specifications. Table 3 illustrates the performance indices for POELC using PIC and LQR. The value of Integral Absolute Error (IAE) is reduced from 5 with PIC and 0.3 with LQR in the servo region. Similarly, the value of IAE is reduced from 7 with PIC and 0.5 with LQR in the disturbance region. The minimum steady-state error implies that the system response is better with LQR techniques. Comparing these results, it was observed that $L Q R$ enhances the system with the stable controlled operation and it is efficiently used for 200W SMPS applications.

Table 3. Performance Indices of PIC and LQR for POELC

\begin{tabular}{|c|c|c|c|}
\hline Performance Indices & & PIC & LQR \\
\hline \multirow{4}{*}{ Servo Response } & IAE & 5 & 0.3 \\
\hline & ITAE & 17.5 & 1.5 \\
\hline & ISE & 7 & 0.1 \\
\hline & ITSE & 20 & 0.4 \\
\hline \multirow{4}{*}{ Regulatory Response } & IAE & 7 & 0.5 \\
\hline & ITAE & 20 & 1.4 \\
\hline & ISE & 8 & 0.19 \\
\hline & ITSE & 20 & 0.02 \\
\hline
\end{tabular}

\section{CONCLUSION}

POELC operated in boost mode has been designed for SMPS applications. This system is evaluated in terms of two controller topologies such as PIC and LQR. System performance is successfully improved by using LQR with and without delay. By using feed-forward and feedback control techniques in LQR, the system open-loop poles are investigated and it moves towards the LHP. Results obtained reveals that the ISE and IAE values are lower with LQR than PIC. The results concluded that the designed converter is best suitable for SMPS applications.

\section{CONFLICTS OF INTEREST}

No conflict of interest was declared by the authors.

\section{REFERENCES}

[1] Achiammal, B., Thillaikarasi, M., "Performance Analysis of PI controller for power electronic Converter usinng evolutionary algorithm", International Journal of Advance Research in Science and Engineering, 7(2): 1132-1140, (2018).

[2] Luo, F., Ye, H., Rashid, M. H., "Multiple-quadrant Luo-converters”, IEE Proceedings-Electric Power Applications, 149(1): 9-18, (2002).

[3] Luo, F., Ye, H., "Positive output cascade boost converters", IEE Proceedings- Electric Power Applications, 151: 590-606, (2004).

[4] Ibrahim, M. A., "Performance evaluation of PI controller for positive output Luo converter", International Journal Power Electronics and Drive System, 11: 1816-1825, (2020).

[5] Nouri, T., Hosseini, S., H., Babaei, E., Ebrahimi, J., "A non-isolated three- phase high step-up DC-DC converter suitable for renewable energy systems", Electric Power Systems Research, 140: 209-224, (2016). 
[6] Kaouane, M., Boukhelifa, A., Cheriti, A., "Regulated output voltage double switch buck-boost converter for photovoltaic energy application", International Journal of Hydrogen Energy, 41(45): 20847-20857, (2016).

[7] Ramash Kumar, K., Jeevananthan, S., "PI control for positive output elementary super lift luo converter", World Academy of Science, Engineering and Technology, 39(3): 732-737, (2009).

[8] Rebeiro, R. S., Uddin, M. N., "Performance analysis of an FLC-based online adaptation of both hysteresis and PI controllers for IPMSM drive", IEEE Transactions on Industry Applications, 48(1): 12-19, (2011).

[9] Singh, S., Sharma, D. K., Kishore, K., Botre, B.A., Akbar, S. A., "Modeling, simulation, and implementation of fast settling switched PI controller for MOX integrated Pt micro heater", IEEE Sensors Journal, 18(20): 8549-8557, (2018).

[10] Renwal, D., Kumar, M., "Hybrid PI-fuzzy logic controller based DC-DC converter", Proceedings of the 2015 International Conference on Green Computing and Internet of Things, ICGCIoT 2015, 1: 753-757, (2016).

[11] Chincholkar, S. H., Chan, C. Y., "Comparative study of current-mode controllers for the positive output elementary Luo converter via state-space and frequency response approaches", IET Power Electronics, 8(7): 1137-1145, (2015).

[12] Jazi, H. N., Goudarzian, A., Pourbagher, R., Derakhshandeh, S.Y., "PI and PWM sliding mode control of POESLL converter", IEEE Transactions on Aerospace and Electronic Systems, 53(5): 2167-2177, (2017).

[13] Mahdavi, M., Shahriari-Kahkeshi, M., Abjadi, N. R., "An adaptive estimator-based sliding mode control scheme for uncertain POESLL converter", IEEE Transactions on Aerospace and Electronic Systems, 55(6), 3551-3560, (2019).

[14] Usharani, V., Agasthiya, R., "Enhanced MPPT technique for DC-DC Luo converter using model predictive control for photovoltaic systems", International Journal of Engineering Research and Development, 11(01), 2278-67, (2015).

[15] Wang, B., Kanamarlapudi, V. R. K., Xian, L., Peng, X., Tan, K. T., So, P. L., "Model predictive voltage control for single-inductor multiple-output DC- DC converter with reduced cross regulation", IEEE Transactions on Industrial Electronics, 63(7): 4187-4197, (2016).

[16] Montagner, V. F., Fabricio, H. D., "A robust LQR applied to a boost converter with response optimized using a genetic algorithm”, XVIII Brazilian Congress of Automatics, 2297-2302, (2010).

[17] Abdullah, M. A., Tan, C. W., Yatim, A. H., "A simulation comparison of PI and linear quadratic regulator controllers in DC-DC converter", IEEE Conference on Energy Conversion, 1: 37-41, (2015).

[18] Murad, M.A.A., Milano, F., "Modelling and simulation of PI-controllers limiters for the dynamic analysis of VSC-based devices", IEEE Transactions on Power Systems, 8950(c): 1-9, (2019).

[19] Luo, F. L., Ye, H., "Advanced DC / DC Converters", 3rd Edition, CRC Press, Boca Raton, USA, (2004). 
[20] Mohan, N., Underland, T., Robbins, W., "Power electronics - converters, applications and design", 2nd Edition, John Wiley and Sons Inc, USA, (2003).

[21] Lindiya, A., Palani, S., Iyyappan, M.,"Performance comparison of various controllers for DC-DC synchronous buck converter”, Procedia Engineering, 38: 2679-2693, (2012).

[22] Guo, L., Hung, J. Y., Nelms, R. M., "Comparative evaluation of sliding mode fuzzy controller and PID controller for a boost converter", Electric Power Systems Research, 81(1): 99-106, (2011).

[23] Paraskevopoulos, P.N., "Modern control engineering", 1st Edition, CRC Press, (2001).

[24] Ogata, K., "Modern control engineering", 5th Edition, Prentice Hall, (2017). 